\title{
ESTUDO SOBRE OS FATORES QUE CONTRIBUEM NO ACIDENTE DE TRÂNSITO NA CIDADE DE NAMPULA
}

\section{STUDY ON THE FACTORS THAT CONTRIBUTE TO THE TRAFFIC ACCIDENT IN THE CITY OF NAMPULA}

António Gonçalves Fortes ${ }^{1}$, Agacane Adelino Mamudo², Momade Jaime Chau³ ${ }^{3}$ Ernesto Taperero Fernando 4

Obs: Foi mantida a gramática original do Português de Moçambique.

\author{
Submetido: $30 / 12 / 2020$ \\ Aprovado: 21/01/2021
}

\section{RESUMO}

A sinistralidade rodoviária urbana é um problema grave em Moçambique, sobretudo nos maiores centros urbanos. Na cidade de Nampula, a sinistralidade rodoviária é um problema social, económico, de desenvolvimento e de saúde pública. Por esse motivo, investigar sobre os fatores que contribuem nos acidentes de trânsito é importante para o estudo dos mecanismos para prevenir futuras ocorrências. O trabalho teve como objetivo identificar os fatores que contribuem nos acidentes de trânsito na cidade de Nampula, e através destes, descrever e caracterizar o problema, para além de propor soluções locais. O estudo foi descritivo e explicativo, de abordagem qualitativa, onde analisou-se, através de observação e questionário dirigido a 106 munícipes, os períodos, os locais, os tipos e os principais fatores que contribuem os acidentes de trânsito. Os resultados mostram que os acidentes de trânsito mais frequentes na cidade são do tipo choque carro-mota e choque de moveis com obstáculos fixos. Estes, são comuns durante os períodos da tarde e noite, nos cruzamentos e entroncamentos. Identificou-se ainda que, as circunstâncias da via, defeitos no percurso, defeitos mecânicos nos veículos, o alcoolismo e o excesso de velocidade ou velocidade inadequada, são os fatores que contribuem nos acidentes de trânsito na cidade de Nampula. Conclui-se que, a melhoria das condições das vias, a educação cívica e responsabilização dos automobilistas são os principais recursos para redução dos acidentes de trânsito em Nampula.

PALAVRAS CHAVES: Segurança viária. Acidente de trânsito. Fatores contribuintes nos acidentes.

\begin{abstract}
Urban road accidents are a serious problem in Mozambique, especially in the largest urban centers. In the city of Nampula, road accidents are a social, economic, development and public health problem. For this reason, investigating the factors that contribute to traffic accidents is important for studying the mechanisms to prevent future occurrences. The work aimed to identify the factors that contribute to traffic accidents in the city of Nampula, and through them, describe and characterize the problem, in addition to proposing local solutions. The study was descriptive and explanatory, with a qualitative approach, where it was analyzed, through observation and a questionnaire addressed to 106 residents, the periods, the places, the types and the main factors that contribute to traffic accidents. The results show that the most frequent traffic accidents in the city are car-motorcycle crash and furniture crash with fixed obstacles. These are common during the afternoon and night, at intersections and junctions. It was also identified that the circumstances of the road, defects in the route, mechanical defects in vehicles, alcoholism and excessive speed or inadequate speed, are the factors that contribute to traffic accidents in the city of Nampula. It is concluded that the improvement

\footnotetext{
1 Mestre em Eng. Geológica. Docente da Faculdade de Ciências Naturais, Estatística e Matemática, Extensão de

Nampula, Campus de Napipine. Universidade Rovuma, Moçambique.

2 Mestrando em Educação/Ensino de Ciências Naturais e Matemática na UniRovuma - Nampula. Docente de Física

${ }^{3}$ Mestrando em Educação/Ensino de Ciências Naturais

${ }^{4}$ Graduado em Ensino de Física com habilitações em Energias Renováveis
} 


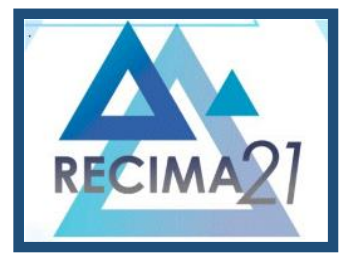

\section{RECIMA21 - REVISTA CIENTÍFICA MULTIDISCIPLINAR}

ESTUDO SOBRE OS FATORES QUE CONTRIBUEM NO ACIDENTE DE TRÂNSITO NA CIDADE DE NAMPULA

António Gonçalves Fortes, Agacane Adelino Mamudo, Momade Jaime Chau, Ernesto Taperero Fernando

of road conditions, civic education and accountability for motorists are the main resources for reducing traffic accidents in Nampula.

KEYWORDS: Road safety. Traffic accident. Contributing factors in accidents.

\section{INTRODUÇÃO E CONTEXTO}

A segurança rodoviária constitui, entre outros aspetos, um grande desafio para Moçambique. Isto porque os números de acidentes de trânsito no país são muito elevados (Shenga et al., 2014). Nas cidades moçambicanas, o crescimento acelerado e desproporcional do número de veículos automóveis em circulação nas estradas, sem, no entanto, se fazer acompanhar pela devida expansão ou melhoramento da rede viária existentes, tornando-as superlotadas e perigosas para a circulação, agravando-se a sua perigosidade, em alguns casos, pela precariedade das vias, má conservação e falta de sinais de trânsito (Adelaide \& Matsimbe, 2017; Manjate, 2012).

As lesões causadas por acidentes de trânsito são um grande problema social, económico, de desenvolvimento e de saúde pública. No mundo, os acidentes de trânsito vitimam vidas de mais de 1,3 milhões de pessoas e pelo menos 50 milhões de pessoas ficam feridas nas estradas todos os anos. Os países em desenvolvimento e as economias em transição suportam a maior parte deste peso, pelo que os acidentes de trânsito são uma questão em desenvolvimento que afeta desproporcionalmente as pessoas pobres nesses países (Nações Unidas, 2010).

Assim sendo, a segurança rodoviária é importante para o desenvolvimento humano. Nenhum desenvolvimento pode ocorrer enquanto a população não estiver protegida dos acidentes de trânsito. A proteção da vida humana constitui o pilar do desenvolvimento. Isso sugere que em Moçambique, a redução da pobreza e melhoria das condições de vida passa, entre outros aspetos, por garantir a segurança rodoviária (Fernando, 2020; Shenga et al., 2014).

A necessidade de melhorar a segurança rodoviária tem sido reconhecida pelo sistema das Nações Unidas e dos seus Estados-Membros durante quase 60 anos, e o trabalho intensivo sobre a segurança rodoviária tem vindo a ser realizado por várias organizações globais, incluindo as Comissões Regionais das Nações Unidas, a Organização Mundial da Saúde (OMS) e o Banco Mundial (Nações Unidas, 2010).

Segundo Instituto Nacional de Transportes Terrestres (INATTER), nos últimos anos tem se registado um grande aumento de automóveis e de acidentes de trânsito na cidade de Nampula (Fig. 1), fato que exige atenção e prudência de todos. No entanto, Manguana e Nassabe (2019, p. 4) consideram que o aumento do número de acidentes de trânsito na cidade "[...] como o resultado do crescimento acelerado do parque automóvel, características do condutor do veículo, o estado de vias de acesso, o estado do ambiente e de conservação dos veículos, entre outros". 


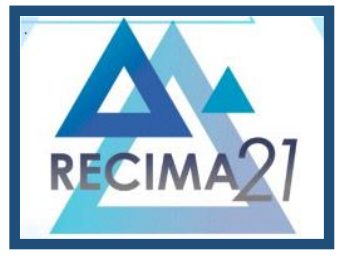

\section{RECIMA21 - REVISTA CIENTÍFICA MULTIDISCIPLINAR}

ESTUDO SOBRE OS FATORES QUE CONTRIBUEM NO ACIDENTE DE TRÂNSITO NA CIDADE DE NAMPULA António Gonçalves Fortes, Agacane Adelino Mamudo, Momade Jaime Chau, Ernesto Taperero Fernando

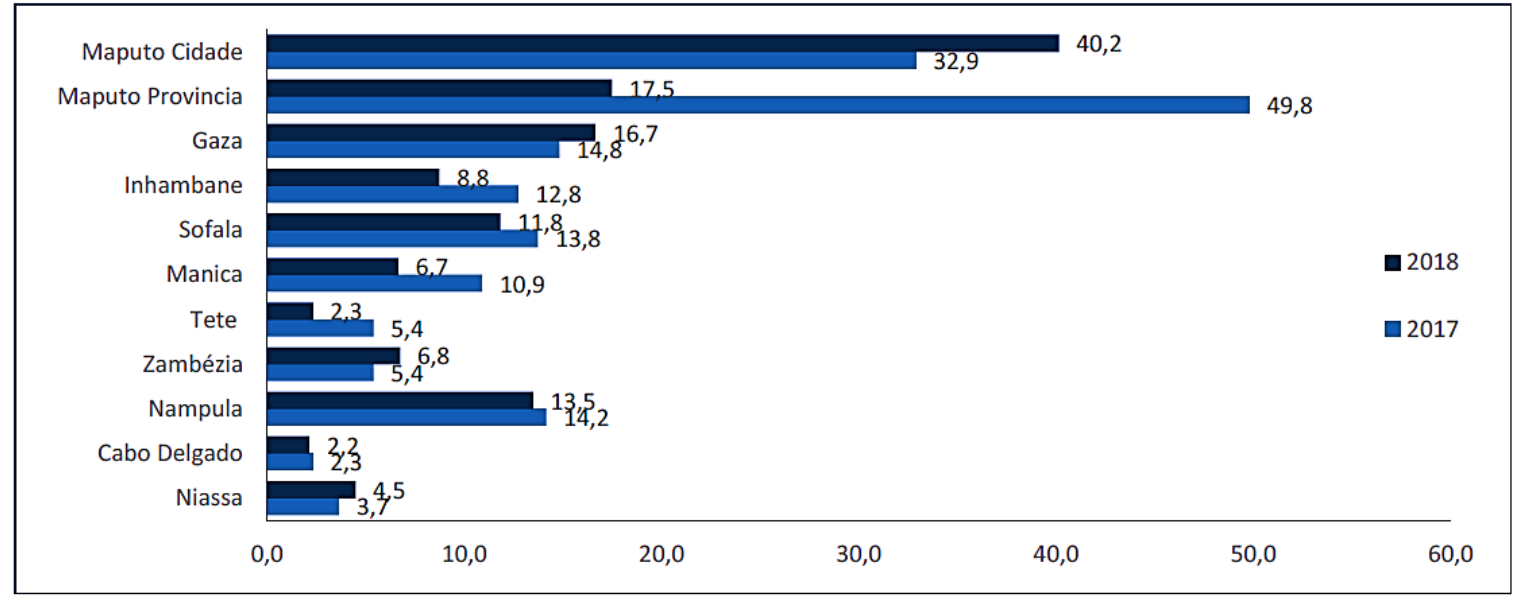

Fonte: Calculado com base em estatísticas correntes da PRM, 2017-2018

Figura 1: Média diária de acidentes de trânsito registrados pelas autoridades policiais, 20172018. Fonte: Manguana \& Nassabe (2019, p. 4)

A escolha do tema foi motivada pelos dados estatísticos, pelos impactos sociais e econômicos nas famílias moçambicanas, para além da racionalidade dos condutores nas vias públicas, visto que, Moçambique lidera o índice de mortes por acidente de trânsito na comunidade de países de língua português (Lutxeque, 2018) e a cidade de Nampula é uma das capitais provinciais com altos níveis de vítimas de acidentes de trânsito, durante o período de 2014-2019 (Manguana \& Nassabe, 2018). Assim sendo, o trabalho teve como objetivo contribuir na melhoria da segurança rodoviária na cidade de Nampula, através da identificação, descrição e caracterização dos principais fatores que contribuem para ocorrência dos acidentes de trânsito na cidade, além de, propor soluções locais para este fenômeno trágico.

\section{LOCALIZAÇÃO GEOGRÁFICA E PERFIL DA CIDADE DE NAMPULA}

Moçambique e um país localizado no Sudeste do continente africano (Fig. 2), situado entre as coordenadas de $10^{\circ} 27^{\prime}$ e $26^{\circ} 56^{\prime}$ de latitude Sul e entre $30^{\circ} 12^{\prime}$ e $40^{\circ} 51^{\prime}$ de longitude Leste. Com uma superfície de 799.380 km² e a população estimada em 29,5 milhões, em 2019 (INE, 2019), o País tem uma densidade populacional média de 35,84 pessoas $/ \mathrm{km}^{2}$. A agricultura é principal atividade económica do País e o transporte rodoviário é o principal modo de transporte, que garante a movimentação de cerca de $60 \%$ de cargas e $90 \%$ de passageiros (MAE, 2014).

A cidade de Nampula é a capital da província do mesmo nome e é considerada um centro regional da região Norte. A área urbana de Nampula (Fig. 2) é a terceira maior do país em termos de população e extensão de infraestruturas. A cidade tem uma população de 743.125 habitantes, segundo o Censo de 2017 e uma área de 404 km² (INE, 2019). Ela está localizada ao longo da linha férrea que liga Nacala a Malawi e a ligação rodoviária para as províncias de Zambézia, Niassa e Cabo Delgado. 


\section{RECIMA21 - REVISTA CIENTÍFICA MULTIDISCIPLINAR}

ESTUDO SOBRE OS FATORES QUE CONTRIBUEM NO ACIDENTE DE TRÂNSITO NA CIDADE DE NAMPULA António Gonçalves Fortes, Agacane Adelino Mamudo, Momade Jaime Chau, Ernesto Taperero Fernando

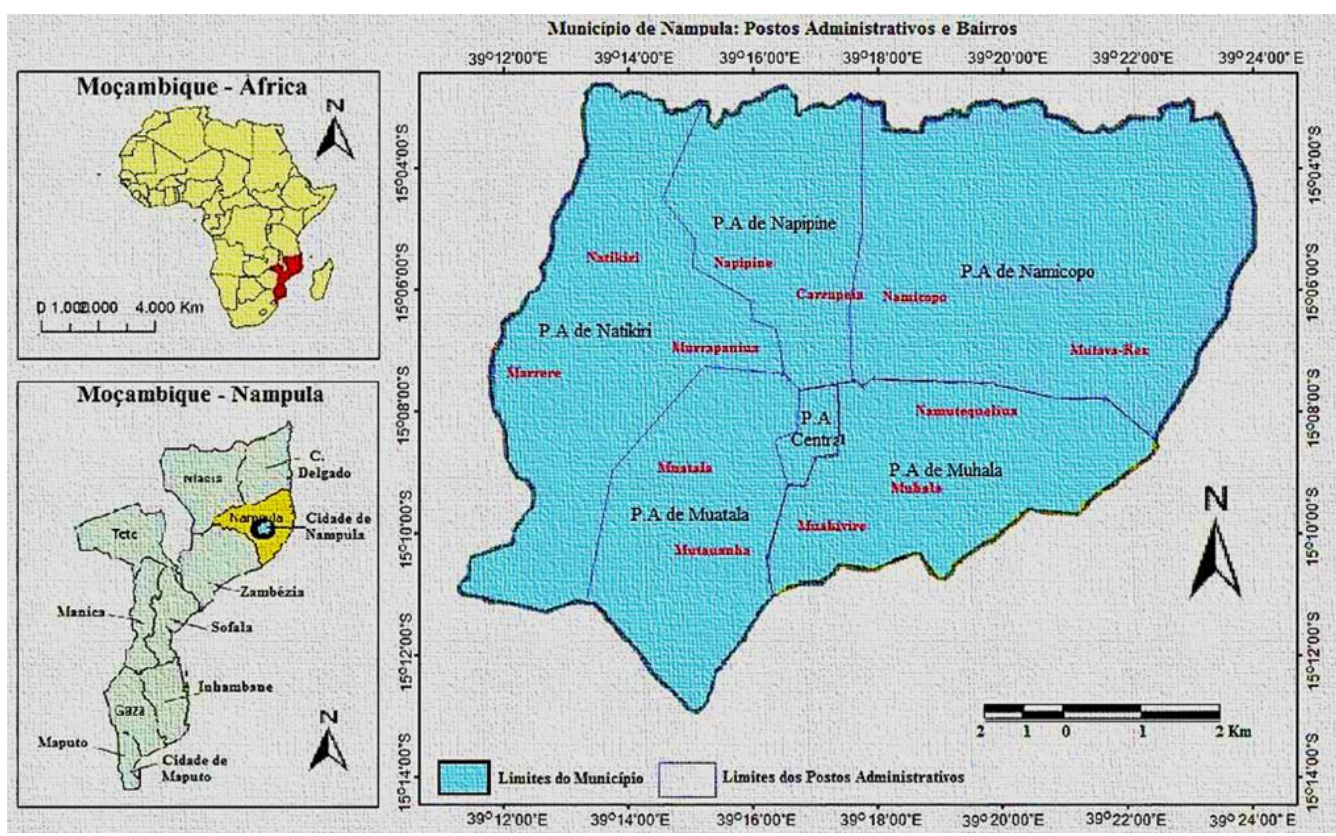

Figura 2. Localização geográfica e divisão administrativa da cidade de Nampula. Adaptado de: (Muacuveia \& Ferreira, 2017).

As estradas moçambicanas são classificadas em: (i) estradas nacionais que compreendem as estradas principais e as estradas secundárias, (ii) e as estradas regionais que compreendem as estradas terciárias, as vicinais, as urbanas e as não classificadas. Em termos de condições de estrada por províncias em 2018, cerca de 70 \% das estrada eram consideradas "boa" ou "razoável" nas províncias de Maputo, Inhambane, Manica e Niassa, enquanto que na província de Nampula menos de $50 \%$ das estradas receberam essa avaliação (ANE, 2018).

A nível da cidade de Nampula, as Polícias de Trânsito (PT) e Municipal (PM), desenvolvem campanhas de educação cívica aos peões para fazerem travessias seguras na via pública, sobretudo para crianças em idade escolar e nos locais considerados de maior risco e propensos à ocorrência de acidentes de trânsito. A presença da PT e MP nestes locais visa corrigir algumas irregularidades cometidas pelos automobilistas, caso do não respeito aos sinais de trânsito e a condução em estado de embriagues e à alta velocidade em locais não apropriados e admissíveis por lei, como nos arredores das escolas e mercados.

\section{REVISÃO DE LITERATURA}

Neste capítulo, será feita a descrição do código de estrada vigente em Moçambique, os fatores e causas dos acidentes de trânsito e os elementos que influenciam na segurança rodoviária, que servirão como suporte teórico para análise do tema. 


\section{RECIMA21 - REVISTA CIENTÍFICA MULTIDISCIPLINAR}

ESTUDO SOBRE OS FATORES QUE CONTRIBUEM NO ACIDENTE DE TRÂNSITO NA CIDADE DE NAMPULA António Gonçalves Fortes, Agacane Adelino Mamudo, Momade Jaime Chau, Ernesto Taperero Fernando

\section{O CÓDIGO DE ESTRADA MOÇAMBICANO}

Em 23 março de 2011, o Conselho de Ministros da República de Moçambique aprovou o Decreto-Lei n. 1/2011, o Código de Estrada, revogando, em simultâneo, o anterior Código de 1954, que ainda se mantinha em vigor, não obstante ter tido, ao longo dos anos que se seguiram à Independência de Moçambique, em 1975, várias alterações, que resultaram em diversos diplomas dispersos e de difícil consulta.

O ordenamento do trânsito em todas as estradas, compete ao Instituto Nacional de Viação (INAV) e no interior das localidades, aos corpos administrativos ou os conselhos municipais (Moçambique, 2011, art. 9). As vias públicas devem ser convenientemente sinalizadas nos pontos em que o trânsito ou o estacionamento estejam vedados ou sujeitos à restrições e, onde existem obstáculos, curvas, cruzamentos, entroncamentos e passagens de nível ou outras circunstâncias que imponham aos condutores precauções especiais (Moçambique, 2011, § 1ํaㄴ. art. 12).

Quanto a distância entre os veículos, o Código estabelece que o condutor de um veículo em marcha deve manter entre o seu veículo e o que o antecede ou que transitam na mesma faixa de rodagem, a distância suficiente para evitar acidente em caso de súbita paragem ou diminuição de velocidade (Moçambique, 2011, art. 20).

Em termos de penalização, o Código fixa que quem exceder os limites máximos de velocidade será punido com pena de multa, que varia em função do tipo de veículo e do fato da infração ser cometida, dentro ou fora das localidades. As contravenções classificam-se de leves (multa de $1.000,00$ meticais $-\mathrm{MT}^{1}$ ), média (multa de 2.000,00 MT) e grave (multa entre 4.000,00 a $8.000,00$ MT) (Moçambique, 2011, § 2º, art. 33).

No que diz respeito a condução sobre a influência de álcool e estupefacientes, foram introduzidas disposições especiais para a fiscalização da condução sob influência dessas substâncias. Para além dos testes de álcool por expiração ou exame de sangue, o Código prevê ainda que, sendo o resultado do exame positivo, o condutor seja impedido de conduzir pelo período de 12 horas e o veículo seja imobilizado ou removido para parque ou outro local apropriado (Moçambique, 2011, art. 82-83).

Considera-se sob a influência de álcool, o condutor que apresente uma taxa de álcool igual ou superior a $0,3 \mathrm{mg} / \mathrm{l}$, no teste de ar expirado ou de $0,6 \mathrm{mg} / \mathrm{l}$, em teste sanguíneo (Tabela 1). Para os condutores de serviço público ou de transporte de carga perigosa, a taxa de álcool é de $0,0 \mathrm{mg} / \mathrm{l}$ (Moçambique, 2011, § $3^{\circ}-4^{\circ}$, art. 81). Os condutores encontrados a conduzir sob influência de substâncias estupefacientes ou psicotrópicas terão uma multa, de até 2.000,00 MT (Moçambique, 2011, § 10, art. 81).

\footnotetext{
11 dólar dos estados Unidos da America (USD) equivale a 74,15 MT (Metical). Fonte: Banco de Moçambique, http://www.bancomoc.mz/fm mercadosmmi.aspx?id=10 acesso em 28/12/2020.
} 


\section{RECIMA21 - REVISTA CIENTÍFICA MULTIDISCIPLINAR}

ESTUDO SOBRE OS FATORES QUE CONTRIBUEM NO ACIDENTE DE TRÂNSITO NA CIDADE DE NAMPULA António Gonçalves Fortes, Agacane Adelino Mamudo, Momade Jaime Chau, Ernesto Taperero Fernando

Tabela 1. Multas aplicadas para condutores sob efeito de alcool em Moçambique.

\begin{tabular}{cc}
\hline Taxa de álcool & Valor da multa \\
\hline $\begin{array}{c}\text { Superior a } 0,0 \mathrm{mg} / \mathrm{l} \text { até } 0,3 \\
\mathrm{mg} / \mathrm{l}\end{array}$ & $1.500,00 \mathrm{MT}$ \\
\hline De $0,3 \mathrm{mg} / \mathrm{l}$ até $0,40 \mathrm{mg} / \mathrm{l}$ & $2.500,00 \mathrm{MT}$ \\
\hline De $0,4 \mathrm{mg} / \mathrm{l}$ até $0,70 \mathrm{mg} / \mathrm{l}$ & $3.500 .00 \mathrm{MT}$ \\
\hline Mais de $0,71 \mathrm{mg} / \mathrm{l}$ & $5.000,00 \mathrm{MT}$ \\
\hline
\end{tabular}

Fonte: Adaptado do Código de estrada (Moçambique, 2011, § 7º, art. 81).

No artigo 87 mostra-se a obrigatoriedade de usar os cintos e demais acessórios de segurança, nos condutores e passageiros transportados em automóveis. E as crianças menores de 12 anos de idade, devem ser seguras por sistema de retenção homologado e adaptado ao seu tamanho e peso. Para os motociclos e ciclomotores devem proteger a cabeça, usando capacetes de modelo oficialmente aprovado, devidamente ajustado e apertado (Moçambique, 2011, § 1, 2 e 4, art. 87).

\section{FATORES QUE CONTRIBUEM NOS ACIDENTES DE TRÂNSITO EM MOÇAMBIQUE}

Segundo Manguana e Nassabe (2019, p. 4) "Acidente é um acontecimento inesperado e indesejável, que pode resultar em vítimas humanas, materiais ou financeiros, e pode ocorrer no meio rodoviário, marítimo, ferroviário ou aéreo". E de acordo com o Código de Estrada Moçambicano, "Acidente de trânsito, é toda a lesão externa ou interna e toda a perturbação nervosa ou psíquica ou dano patrimonial e moral que resulta da ação de uma violência exterior súbita produzida" (Moçambique, 2011, § 1ํㅡ, art. 151).

Os acidentes rodoviários têm sido tradicionalmente, vistos como o resultado da interação de quatro fatores do sistema rodoviário: humano, veicular, institucional e viário (tabela 2). Sendo as ações do homem (peão, motorista e agentes de PT e PM), respostas aos estímulos fornecidos pelo ambiente viário (Adelaide \& Matsimbe, 2017). Para além do fator humano, os aspetos ligados a via são responsáveis pela ocorrência de acidentes de trânsito, cuja correção contribuiria para a redução de grande número de sinistros (Adelaide \& Matsimbe, 2017; Nhamire \& Mabunda, 2014).

Tabela 2. Descrição dos principais fatores que influenciam nos acidentes de trânsito.

\begin{tabular}{cl}
\hline Fator & Descrição \\
\hline \multirow{3}{*}{ Veicular } & $\begin{array}{l}\text { São os fatores relacionados diretamente ao automóvel desde o projeto } \\
\text { de segurança e fabricação até as questões de manutenção e } \\
\text { conservação do veículo, sendo eles, as falhas do sistema de freios, } \\
\text { má conservação dos pneus, problemas com a suspensão e o não } \\
\text { acionamento dos airbags. }\end{array}$ \\
\hline \multirow{2}{*}{ Humano } & $\begin{array}{l}\text { Refere-se as inúmeras atribuições que afetam o comportamento } \\
\text { humano nue consiste o ambiente de tráfego, indo desde aspectos } \\
\text { mais amplos como a condição social, sexo, idade, físico e psicológico, } \\
\text { até os aspectos mais singulares como inexperiência, personalidade ou } \\
\text { deficiências. }\end{array}$ \\
\hline \multirow{3}{*}{ Comportamentais } & $\begin{array}{l}\text { Resume-se às características psicológicas do homem, como a } \\
\text { personalidade do motorista no trânsito, a educação da sociedade ao } \\
\text { entorno das vias, a prudência dos ciclistas, as noções de }\end{array}$
\end{tabular}

ISSN: 2675-6218 - RECIMA21 - Ciências Exatas e da Terra, Sociais, da Saúde, Humanas e Engenharia/Tecnologia 


\section{RECIMA21 - REVISTA CIENTÍFICA MULTIDISCIPLINAR}

ESTUDO SOBRE OS FATORES QUE CONTRIBUEM NO ACIDENTE DE TRÂNSITO NA CIDADE DE NAMPULA

António Gonçalves Fortes, Agacane Adelino Mamudo, Momade Jaime Chau, Ernesto Taperero Fernando

\begin{tabular}{|c|c|}
\hline & responsabilidades dos pedestres etc. \\
\hline Cognitivos & $\begin{array}{l}\text { Relaciona-se às características de aprendizado ou inexperiência do } \\
\text { homem. Estes estão ligados ao grau e tempo de instrução do } \\
\text { motorista e o grau de conhecimento das regras de trânsito na } \\
\text { sociedade em geral. }\end{array}$ \\
\hline Fisiológicos & $\begin{array}{l}\text { Concerne ao grau de alteração das funções corporais do homem: } \\
\text { questões de embriaguez, estresse, sonolência, efeito de } \\
\text { medicamentos, cansaço e deficiências físico-motoras. }\end{array}$ \\
\hline Institucionais & $\begin{array}{l}\text { Nesse fator estão incluídos, a regulamentação e a fiscalização, por } \\
\text { exemplo, a inadequação do treinamento dos condutores, as lacunas } \\
\text { de informação, insuficientes diretrizes do Código de Estrada e as } \\
\text { questões de falta de fiscalização ou presença policial nas vias e a } \\
\text { impunidade das situações pós-acidentes. }\end{array}$ \\
\hline Ambientais & $\begin{array}{l}\text { Os principais fatores ambientais são: chuva e neve, que reduzem a } \\
\text { aderência na pista, ventos intensos, neblina e o período de variação } \\
\text { entre dia e noite, uma vez que o guia do automóvel fica suscetível à } \\
\text { redução da luminosidade e visibilidade. }\end{array}$ \\
\hline Viário & $\begin{array}{l}\text { O ambiente viário se mal projetado pode criar situações propícias a } \\
\text { acidentes. Compõem os fatores viários, o projeto geométrico, } \\
\text { sinalização, condições da pavimentação, funcionalidade dos } \\
\text { dispositivos de drenagem e as características urbanas da via. }\end{array}$ \\
\hline Circunstanciais & $\begin{array}{l}\text { Relativas a circunstâncias alheias às anteriores: aquelas que não } \\
\text { podem ser enquadradas nos grupos anteriores, por exemplo um inseto } \\
\text { que se introduz no interior do veículo, a pedra que quebra o para- } \\
\text { brisas e árvore que cai por cima do veículo em movimento. }\end{array}$ \\
\hline Imediatas & $\begin{array}{l}\text { Relativo ao excesso de velocidade, ou velocidade inadequada e } \\
\text { outras infracções as normas de circulação; condições pessoais } \\
\text { negativas; erros de evasão; deficiências na percepção; e outras. }\end{array}$ \\
\hline
\end{tabular}

Adaptado de (Machava, 2011; Manguana \& Nassabe, 2018).

Machava (2011, p. 9) acrescenta que a segurança no sistema de transporte rodoviário depende do equilíbrio entre a interação das exigências do ambiente e as capacidades de resposta do condutor. Ou seja, se o ambiente deve induzir no condutor uma conduta adequada, a informação na via deve ser adequada para que o condutor possa tomar precauções mais corretas em função da infraestrutura da estrada, sendo certo que esta deve ser construída tendo em conta as limitações do ser humano.

O principal problema das redes rodoviárias moçambicanas é a desproporção das suas condições relativamente aos progressos técnicos comportados pelos veículos. Deparamo-nos com deficiências de várias ordens nomeadamente, estradas antigas, inconsistências ao nível do projeto, falta de qualidade na construção desenhada, curvas com baixa visibilidade e construídas para veículos de baixa velocidade, de reduzidas cargas e de pequenas dimensões (Fernando, 2020; Machava, 2011). Um estudo conjunto realizado pelos ministérios dos Transportes e Comunicações, do Interior e das Obras Públicas e Habitação, consideram principais causas de acidentes: a má circulação e travessia de peões, deficiente sinalização das vias públicas, excesso de velocidade, condução sob efeito de álcool, ultrapassagem irregular, trânsito fora da mão, deficiência mecânica dos veículos e transporte de passageiros em veículos não apropriado. E Adelaide e Matsimbe (2017) associam os sinistros rodoviários nas vias interurbanas moçambicanas com as deficiências no projeto geométrico da via, 


\section{RECIMA21 - REVISTA CIENTÍFICA MULTIDISCIPLINAR}

ESTUDO SOBRE OS FATORES QUE CONTRIBUEM NO ACIDENTE DE TRÂNSITO NA CIDADE DE NAMPULA António Gonçalves Fortes, Agacane Adelino Mamudo, Momade Jaime Chau, Ernesto Taperero Fernando ocupação indevida de terrenos na área adjacente as vias e as deficiências na secção transversal, no pavimento, na drenagem das vias e na sinalização.

\section{SEGURANÇA RODOVIÁRIA EM NAMPULA}

A sinalização rodoviária é um sistema constituído por dispositivos e equipamentos destinada a assegurar a segurança dos utentes nas rodovias (Amodo \& Zandamela, 2019). O Código de estradas estabelece que: "Nenhuma via pavimentada pode ser entregue após sua construção, ou reaberta ao trânsito após a realização de obras ou de manutenção, enquanto não estiver devidamente sinalizada, vertical e horizontalmente, de forma a garantir as condições adequadas de segurança na circulação" (Moçambique, 2011, § 5º, art. 6).

Shenga et al. (2014, p. 3) descreve os principais itens que constam na segurança rodoviária, segundo a política rodoviária em Moçambique:

Sinalização rodoviária: uma eficiente sinalização rodoviária pode garantir a segurança rodoviária, aumentando as chances dos automobilistas e peões não se envolverem em acidentes. Todavia, o parque automobilístico da cidade de Nampula é caracterizado por rodovias cujas sinalizações são deficitárias: (i) alguns semáforos não funcionam e não existir um polícia no local para regular o trânsito; (ii) as passadeiras dos peões não estão sinalizadas; (iii) algumas rotundas não estão sinalizadas ou distinguidas com as devidas cores.

Educação rodoviária nas escolas: as crianças dotadas de conhecimentos sobre segurança rodoviária, atravessam as estradas em locais seguros (o exemplo das passadeiras). Contudo, em Nampula é frequente ver crianças e adolescentes: (i) atravessar a estrada correndo; (ii) deixar as passadeiras, para atravessar a estrada em locais inseguros; (iii) desorientadas para atravessar a estrada; e (iv) sem um guia para Ihes ajudar a atravessar a estrada.

Formação de automobilistas: os automobilistas com conhecimentos sólidos ou bem formados na área de segurança rodoviária minimizam a sinistralidade rodoviária, tem maior prudência rodoviária e cometem menos irregularidades. Porém, na cidade de Nampula é frequente observar automobilistas que: (i) não param no sinal vermelho do semáforo; (ii) não respeitam a passadeira dos peões no semáforo; (iii) iniciam a marcha enquanto o sinal vermelho ainda está visível; (iv) param ou mesmo estacionam na faixa de rodagem; (v) não sinalizam quando viram a esquerda ou a direita; (vi) fazem ultrapassagens irregulares; (vii) cortam prioridade a outras viaturas; (viii) dirigem viaturas escutando música com volume alto e falam ao celular; (ix) permitem o cobrador do chapa não encartado a transportar passageiros; $(\mathrm{x})$ conduzem veículos não inspecionados ou com sérios problemas mecânicos.

Eficiente implementação do Código de Estradas: uma correta implementação do Código de Estradas pode garantir a segurança rodoviária. Os agentes da PT e PM que fiscalizam veículos e automobilistas corretamente reduzem os índices de acidentes de trânsito. Porém, em Nampula é 


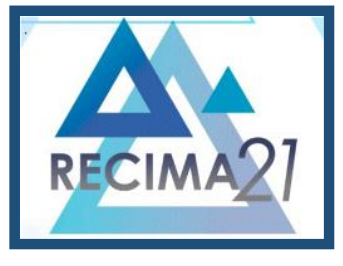

\section{RECIMA21 - REVISTA CIENTÍFICA MULTIDISCIPLINAR}

ESTUDO SOBRE OS FATORES QUE CONTRIBUEM NO ACIDENTE DE TRÂNSITO NA CIDADE DE NAMPULA António Gonçalves Fortes, Agacane Adelino Mamudo, Momade Jaime Chau, Ernesto Taperero Fernando frequente deparar-se com esses agentes que: (i) deixam passar veículos sem iluminação, sinalização ou não inspecionados, a troca de favores; e (ii) deixam passar automobilistas em situação irregular.

\section{METODOLOGIA}

Com objetivo de identificar os principais fatores que contribuem para ocorrência dos acidentes de trânsito na cidade de Nampula, realizou-se um estudo descritivo e explicativo, de abordagem qualitativa, uma vez que esta possibilita a melhor interação com o grupo alvo, colhendo-se deste modo, experiências e vivências individuais.

Quanto aos procedimentos, fez-se um estudo bibliográfico para contextualização sobre (i) acidente de trânsito, (ii) fatores que contribuem na ocorrência dos acidentes, (ii) as principais causas dos acidentes de trânsito, (iv) e a segurança rodoviária em Moçambique e em Nampula. O embasamento baseou-se na leitura de livros, artigos científicos, teses e dissertações, sem delimitação temporal e espacial das fontes, porém com afinidades contextuais.

Para análise de dados secundários foi utilizado o estudo documental, o que permitiu o levantamento e a análise de informação no Código de estrada moçambicano e outros documentos legais aplicados na segurança viária.

Para a coleta de dados primários, foi aplicado: (i) a observação direta, que consistiu em visitas regulares a diversos locais da cidade de Nampula, com objetivo de identificar, descrever e caracterizar os tipos de acidentes mais frequentes na cidade. A escolha dos locais foi baseada na quantidade de fluxo de pessoas, bicicletas ou automóveis e no histórico de acidentes de trânsito; (ii) um questionário dirigido a 106 munícipes, que visava colher informação sobre a segurança rodoviária na cidade.

A amostragem foi probabilística aleatória, segundo Yin (2005), selecionada de forma que toda a população tenha as mesmas chances de participar na pesquisa, consoante a disposição no preenchimento do questionário, durante o período que decorreu a pesquisa, de 03 a 31 de agosto de 2020. Após o término do prazo, realizou-se a compilação e análise estatística: frequência relativa simples e percentual.

Os dados foram submetidos a análise de conteúdo, seguindo as seguintes fases: (i) análise preliminar, caraterizada pela descrição de cada variável, possibilitando-se chegar às conclusões parciais; (ii) exploração dos dados e descrição minuciosas das respostas; (iii) e interpretação de cada variável e nível de afinidade, chegando-se as conclusões gerais da pesquisa.

\section{RESULTADOS E ANÁLISES}

O presente capítulo destina-se à apresentação e análise de dados coletados com o auxílio das técnicas de observação e questionários aplicados às fontes no campo.

O ambiente de trânsito na cidade de Nampula é caracterizado pela circulação conjunta de diferentes tipos de espécie de veículos (bicicleta, motas, automóvel e ónibus), veículos de carga (camionete, 


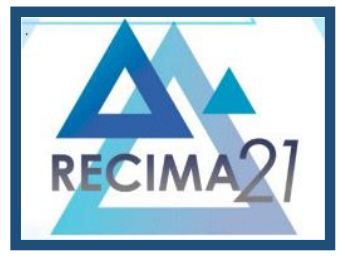

\section{RECIMA21 - REVISTA CIENTÍFICA MULTIDISCIPLINAR}

ESTUDO SOBRE OS FATORES QUE CONTRIBUEM NO ACIDENTE DE TRÂNSITO NA CIDADE DE NAMPULA António Gonçalves Fortes, Agacane Adelino Mamudo, Momade Jaime Chau, Ernesto Taperero Fernando

caminhão, reboque e carrinhas de mão), veículos de tração (tratores) e peões de todas as faixas etárias e género. Na cidade é frequente a circulação de crianças, sem o devido acompanhamento (Fig. 3C) e ocupação dos passeios por vendedores ambulantes e estacionamento de viaturas, o que dificulta a circulação de pessoas e bens. Para circulação dos peões, os passeios não são de boa qualidade e as ruas e avenidas não têm sinalização específica (Fig. 3A e 3C), algumas sem asfalto (Fig. 3D), o que dificulta a circulação na cidade.

O transporte público é feito por transportes municipais e "chapas" (transportes públicos privados), sendo que, alguns operar com viaturas em mau técnico, com lotação excedida e encurtando as rotas nas horas de ponta, nos finais de semana e dias festivos. Para transporte alternativo existem os táxis e o popular táxi-mota (operado pelos mototaxistas), estes últimos (Fig. 3A e 3B), sem noções básicas das regras de trânsito. O conflito por espaço para circulação é tão grande (Fig. 3B) que as estatísticas do INAV mostram que mais de $50 \%$ dos mortos em acidentes, na província de Nampula, são os peões (Lutxeque, 2018; Manguana \& Nassabe, 2019).

Para além da precariedade das vias e falta de iluminação pública (Fig. 3 A-D), alguns trechos estão cobertos parcialmente pelos resíduos sólidos urbanos (Fig. $3 C$ ), situação que interfere na transitabilidade e na estética da urbe.
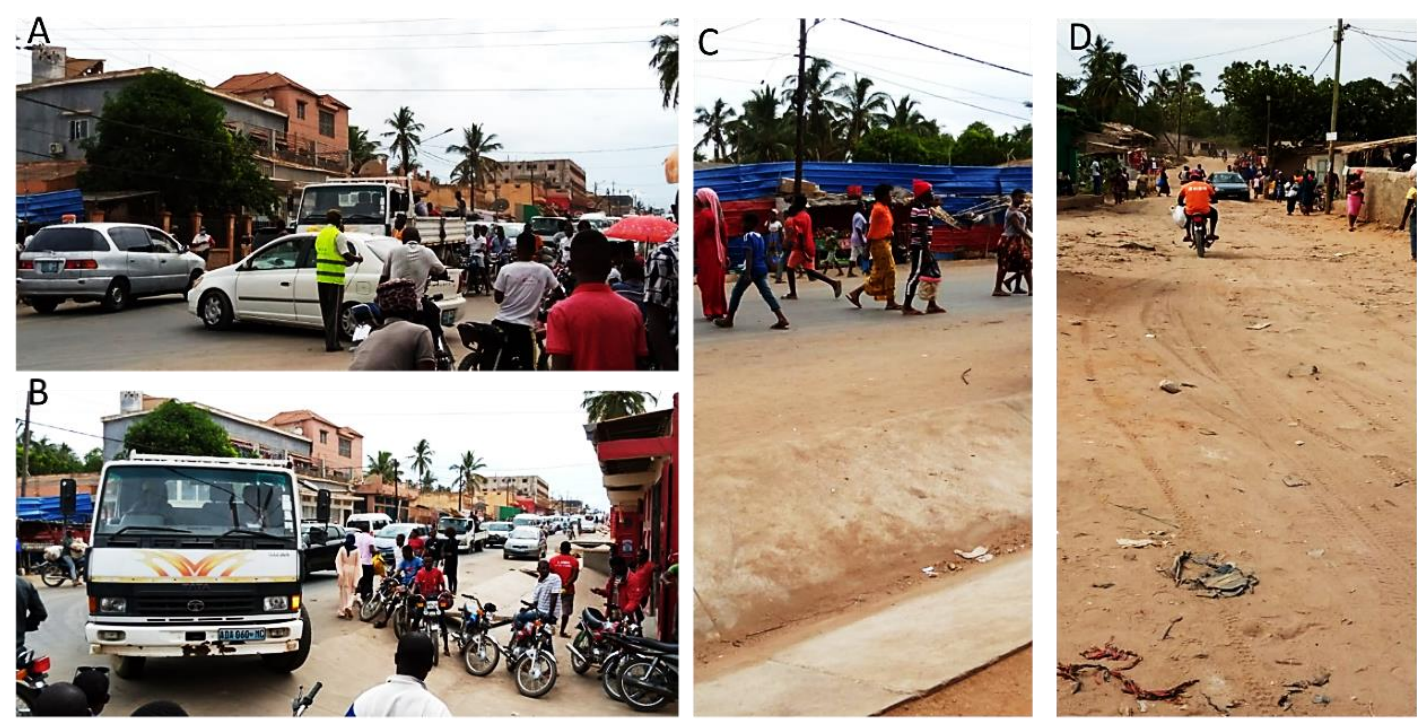

Figura 3. Caracteristicas das vias da urbe. A: Atuação polícia municipal na Av. do Trabalho, próximo a rotunda do aeroporto. Observa-se trânsito caótico e mototaxistas sem capacete de proteção; B: Conflito de espaço entre os mototaxistas e caminhões de carga na região dos Bombeiros, bairro Central; C: Travessia de peões num troço sem sinalização na rodovia N13, na região do mercado Waresta, bairro Natiquiri; D: Vias não classificas, sem asfalto ou pavés, no bairro dos Belenenses.

Foram no total cerca de 106 munícipes que responderam o questionário, sendo 56 peões e 50 condutores (Tabela 3). Em simultâneo, procedeu-se a análise e discussão das respostas obtidas no estudo. 


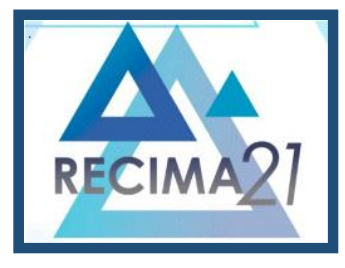

\section{RECIMA21 - REVISTA CIENTÍFICA MULTIDISCIPLINAR}

ESTUDO SOBRE OS FATORES QUE CONTRIBUEM NO ACIDENTE DE TRÂNSITO NA CIDADE DE NAMPULA António Gonçalves Fortes, Agacane Adelino Mamudo, Momade Jaime Chau, Ernesto Taperero Fernando

Tabela 3. Dados sobre a caracteristica da amostra.

\begin{tabular}{|c|c|c|c|c|}
\hline \multirow{2}{*}{\multicolumn{2}{|c|}{ Características da amostra }} & \multicolumn{2}{|c|}{ Local de residência } & \multirow[t]{2}{*}{ Total } \\
\hline & & Zona urbana & Zona suburbana & \\
\hline \multirow[t]{2}{*}{ Peões } & Homens & 11 & 30 & 41 \\
\hline & Mulheres & 9 & 6 & 15 \\
\hline \multirow{2}{*}{ Condutores } & Amadores & 12 & 28 & 40 \\
\hline & Profissionais & 2 & 8 & 10 \\
\hline
\end{tabular}

A idade dos questionados variou de 18 a 47 anos (Fig. 4), ambos da idade adulta, sem inclusão de crianças e adolescentes (menores 18 anos) e idosos (maior de 56 anos). Apurou-se ainda que os jovens ( 18 - 35 anos) constitui a faixa etária que mais oferece ou apresenta riscos, associado ao fato de serem mais ativos, mais presente nas ruas e com maiores possibilidades de exercerem atividades longe das suas residências. Resultados similares foram obtidos por Machava (2011), num estudo realizado na cidade do Maputo.

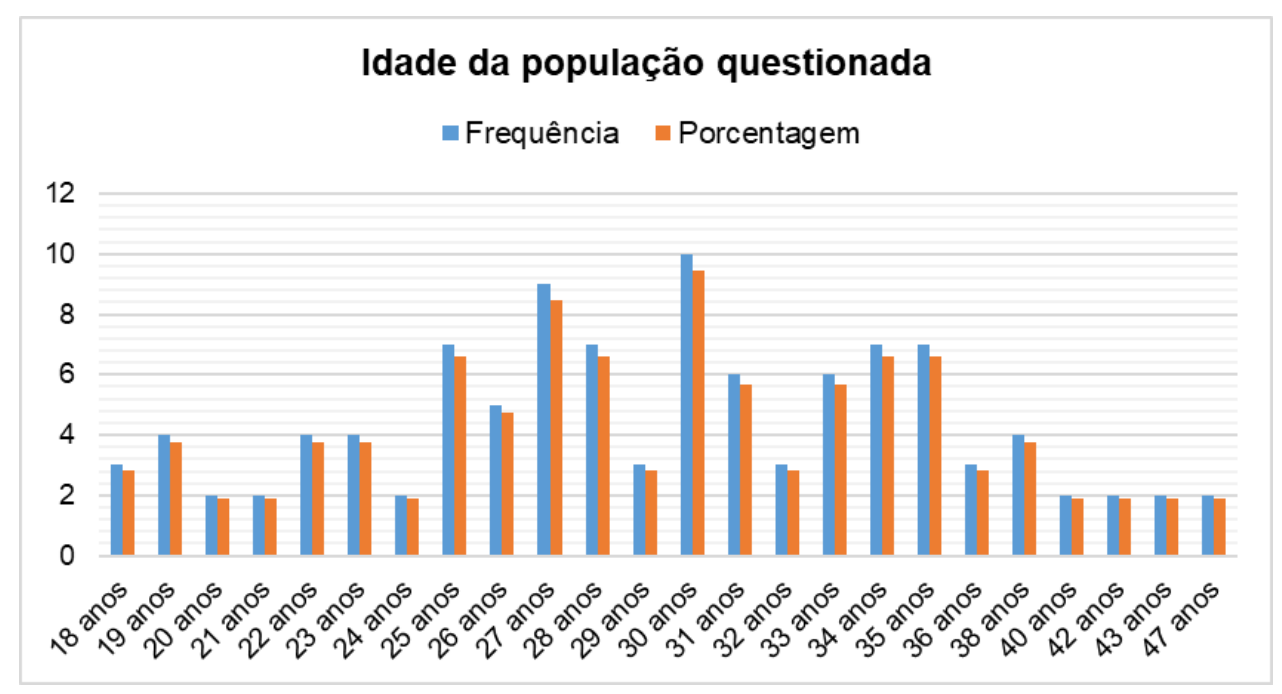

Figura 4. Distribuição da idade da população questionada no estudo.

Houve inclusão de munícipes de todos os postos administrativos (P.A.) urbanos da cidade de Nampula (Fig. 5), embora haja maior incidência de munícipes dos P.A. de Muatala, Muhala e Napipine, e baixa participação dos munícipes dos P.A. da periferia, sobretudo do Anchilo e Namicopo. 


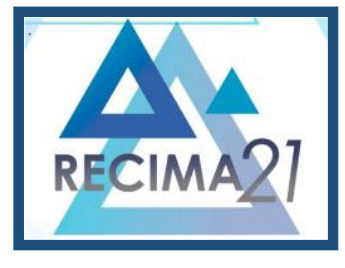

\section{RECIMA21 - REVISTA CIENTÍFICA MULTIDISCIPLINAR}

ESTUDO SOBRE OS FATORES QUE CONTRIBUEM NO ACIDENTE DE TRÂNSITO NA CIDADE DE NAMPULA António Gonçalves Fortes, Agacane Adelino Mamudo, Momade Jaime Chau, Ernesto Taperero Fernando

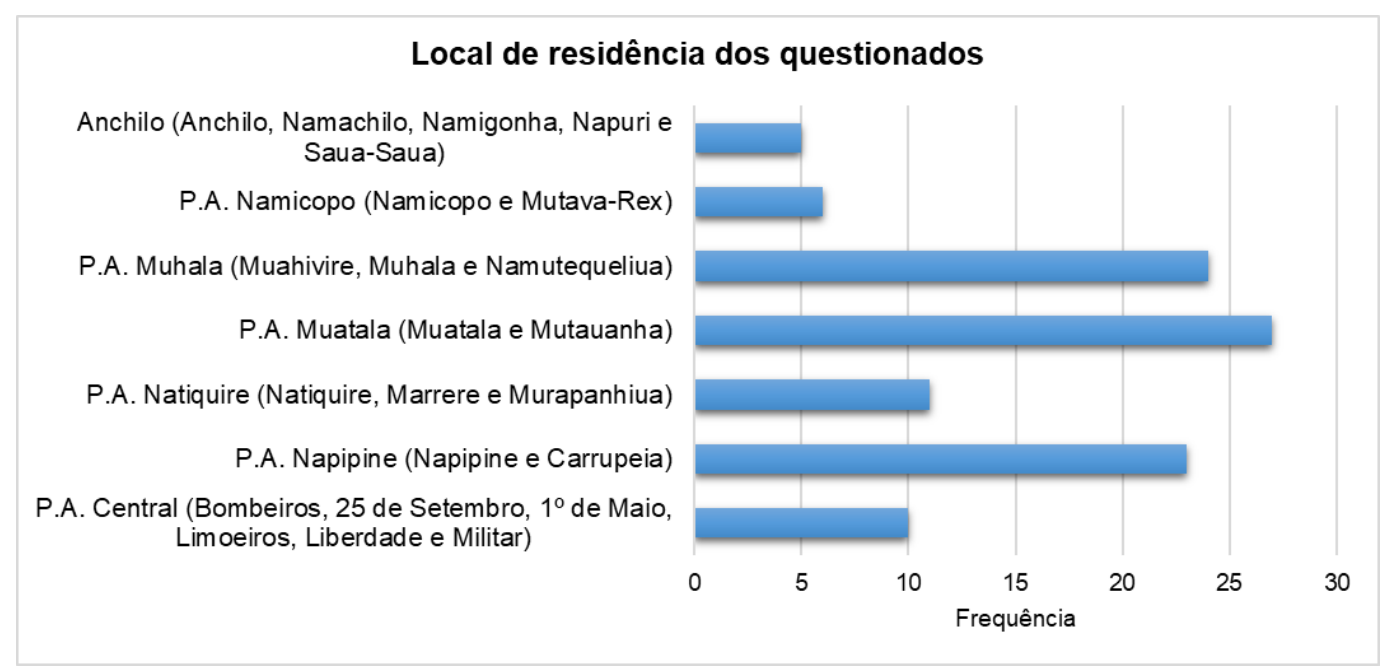

Figura 5. Local de residência dos minícipes questionados.

$\mathrm{Na}$ análise dos períodos diários que mais ocorrem os acidentes (Fig. 6), constatou-se que a maioria dos acidentes (37\%) ocorrem no período da noite, seguido do período da tarde (30\%), manhã (18 $\%)$ e de madrugada (15\%). Essa distribuição pode ter relação com o fluxo de automóveis nas estradas e a presença dos peões nas estradas. O resultado pode estar associado ainda com os fatores humanos, como o alcoolismo, o cansaço, o comportamento dos automobilistas e a imprudência. Nos períodos de tarde e noite é possível que os motoristas tenham pressas para se deslocar na cidade, o que pode resultar no aumento de acidentes de trânsito nesses períodos.

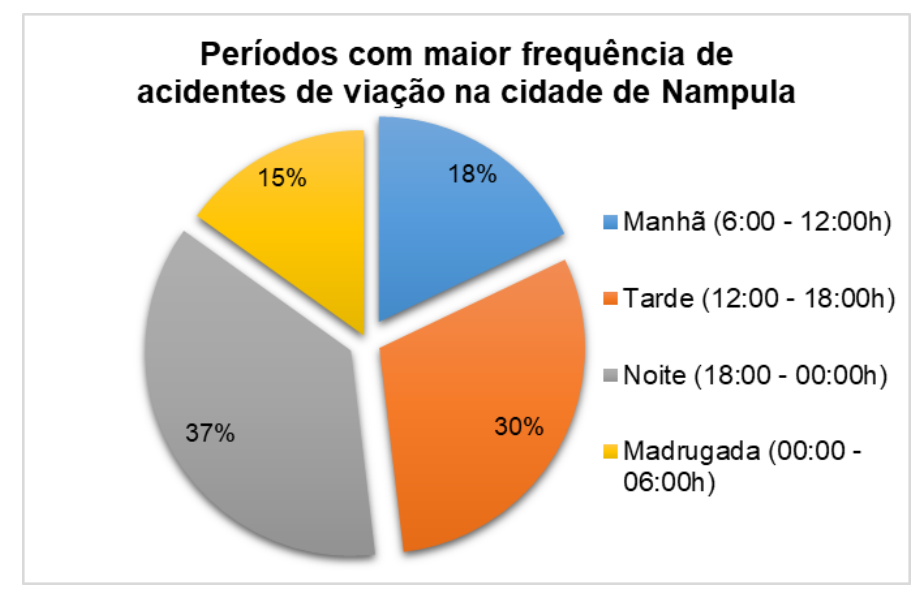

Figura 6. Periodos do dia com maior frequencia de acidentes de trânsito em Nampula. 


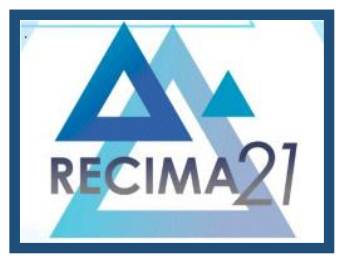

\section{RECIMA21 - REVISTA CIENTÍFICA MULTIDISCIPLINAR}

ESTUDO SOBRE OS FATORES QUE CONTRIBUEM NO ACIDENTE DE TRÂNSITO NA CIDADE DE NAMPULA

António Gonçalves Fortes, Agacane Adelino Mamudo, Momade Jaime Chau, Ernesto Taperero Fernando

Estes acidentes ocorrem com maior frequência nos cruzamentos e entroncamentos (Fig. 7A), correspondendo a $51,5 \%$ dos acidentes, seguido das curvas (28,2\%). Nas ruas e avenidas há baixa frequência dos acidentes. Este fato, associado a falta de sinalização dos cruzamentos e entroncamentos (Fig. 7B e 7C), precariedade das vias e falta de fiscalização dos locais, como foi discutido por Fernando (2020)
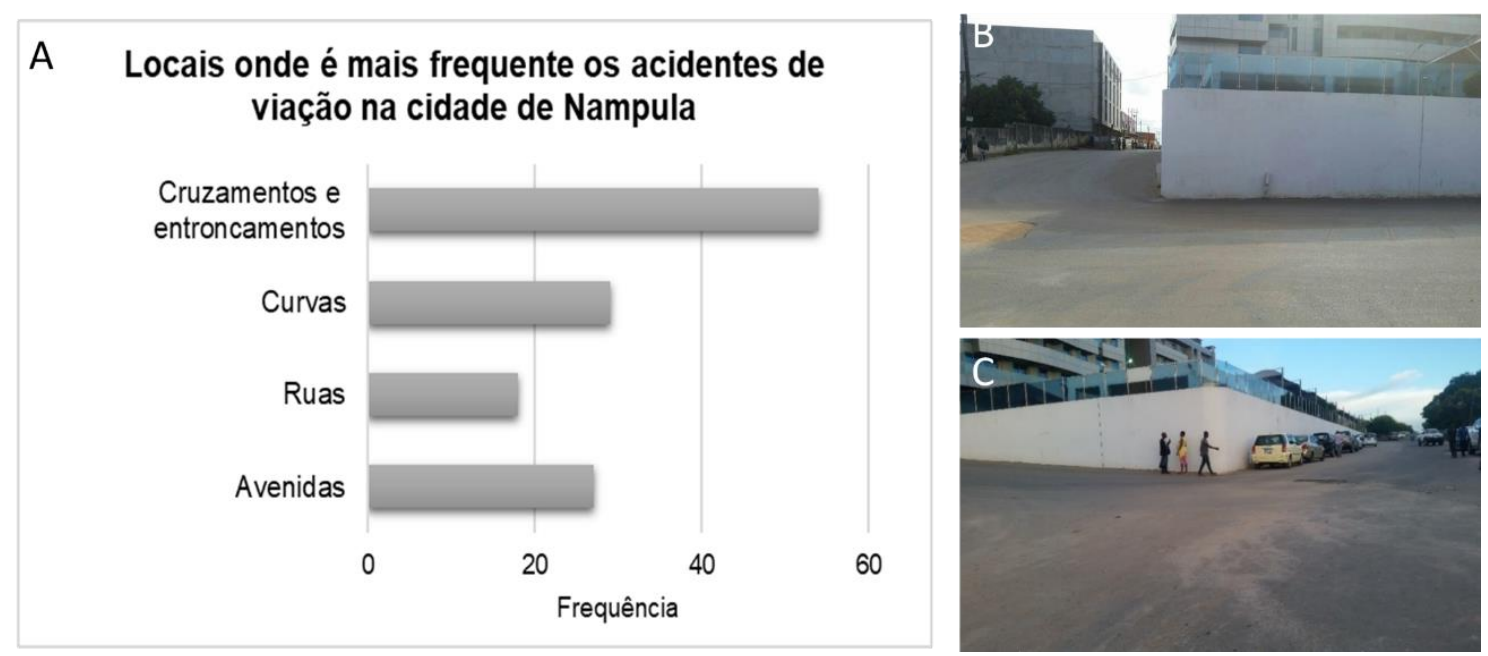

Figura 7. A: Locais onde são mais frequentes os acidentes de trânsito na cidade de Nampula; B e C: Entroncamento entre as Av. Eduardo Mondlane, em direção a Av. do Trabalho. Observa-se um murro de vedação de uma instância hoteleira bastante alto, o que influenciar na visibilidade dos motoristas nos dois sentidos.

Sobre os tipos de acidentes mais frequentes na cidade de Nampula (Fig. 8), consta que o choque entre motas e o choque entre automóveis e obstáculos fixos são os mais frequentes, que perfazem em conjunto, $84,5 \%$ das frequências dos acidentes. Este fato pode ser condicionado principalmente com a crescente utilização dos serviços dos mototaxistas (Tabela 4), alguns desempenhando a atividade de forma ilegal e sem prudência necessária para transporte de passageiros. Outro aspeto notável é a frequência de choque entre automóveis e obstáculos fixos, demostrando-se, deste modo, certa inexperiência dos condutores e falta de atenção na via. 


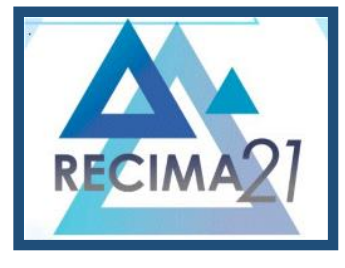

\section{RECIMA21 - REVISTA CIENTÍFICA MULTIDISCIPLINAR}

ESTUDO SOBRE OS FATORES QUE CONTRIBUEM NO ACIDENTE DE TRÂNSITO NA CIDADE DE NAMPULA

António Gonçalves Fortes, Agacane Adelino Mamudo, Momade Jaime Chau, Ernesto Taperero Fernando

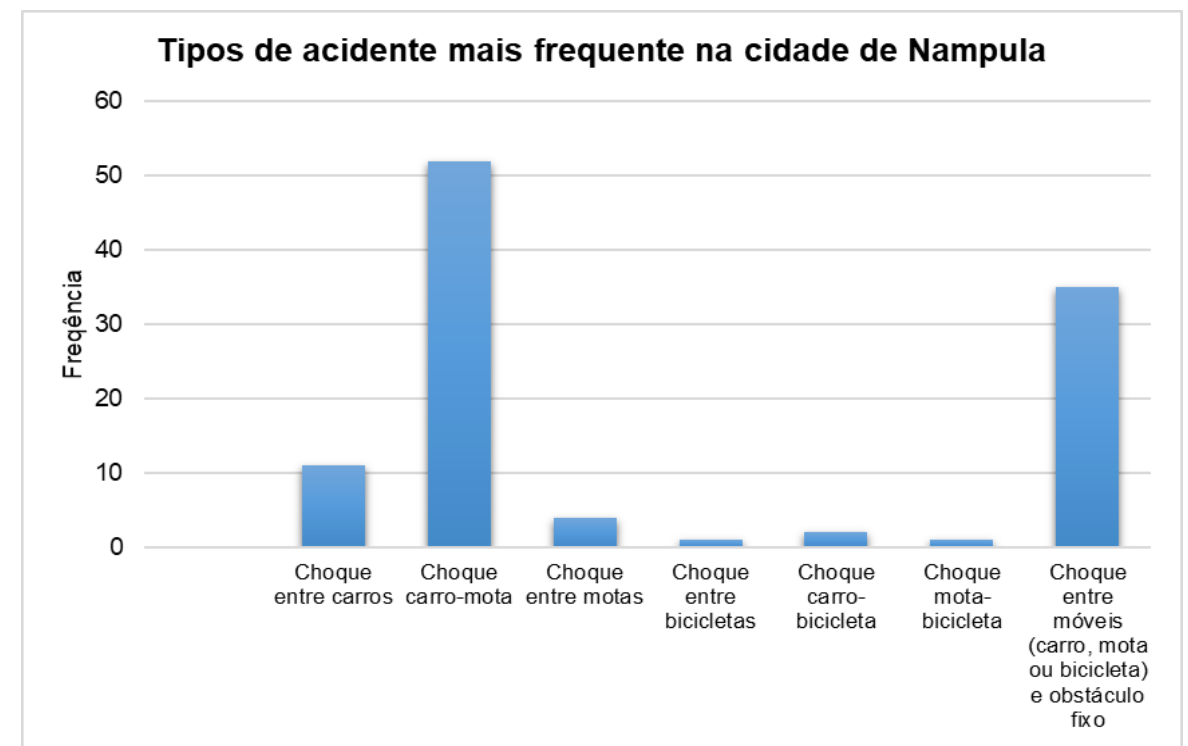

Figura 8. Principais tipos de acidentes de trânsito que ocorrem na cidade de Nampula.

Quanto aos fatores que contribuem nos acidentes de trânsito, na pesquisa agrupou-se em cinco grupos, nomeadamente, fatores ambientais, de estrada, veiculares, humanos e imediatos, que passaremos a analisar em separado.

As circunstâncias da via é o fator ambiental que mais influencia (51\%) nos acidentes de trânsito na cidade de Nampula (Fig. 9), seguida das circunstâncias do ambiente (12\%), das condições de iluminação (9 \%) e condições climáticas (4,6\%).

Entre as circunstâncias da via definidas por Chagas (2011) podemos destacar no estudo, o desgaste da superfície de algumas vias, existência frequentes de obras e manutenção de trechos da via, obstrução da via, deficiência na sinalização, sobretudo de semáforos e a falta de marcação ou marcação apagada das faixas de rodagem. Entre as circunstâncias do ambiente podemos destacar a existência de objetos ou animais na via, deficiência no controlador de tráfego, reflexos e obstruções da via. As condições de iluminação variam desde a variação da luminosidade da luz solar, durante os dias e a deficiência na iluminação pública em algumas áreas, durante as noites. $E$ as condições climáticas locais com possibilidade de ocorrência de acidentes são céu nublado, fumaça, chuva, ventos fortes ou com areia e poeira. 


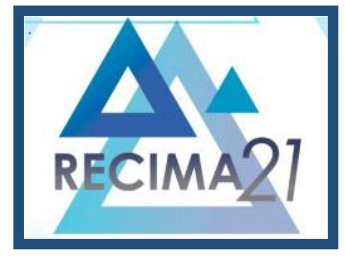

\section{RECIMA21 - REVISTA CIENTÍFICA MULTIDISCIPLINAR}

ESTUDO SOBRE OS FATORES QUE CONTRIBUEM NO ACIDENTE DE TRÂNSITO NA CIDADE DE NAMPULA

António Gonçalves Fortes, Agacane Adelino Mamudo, Momade Jaime Chau, Ernesto Taperero Fernando

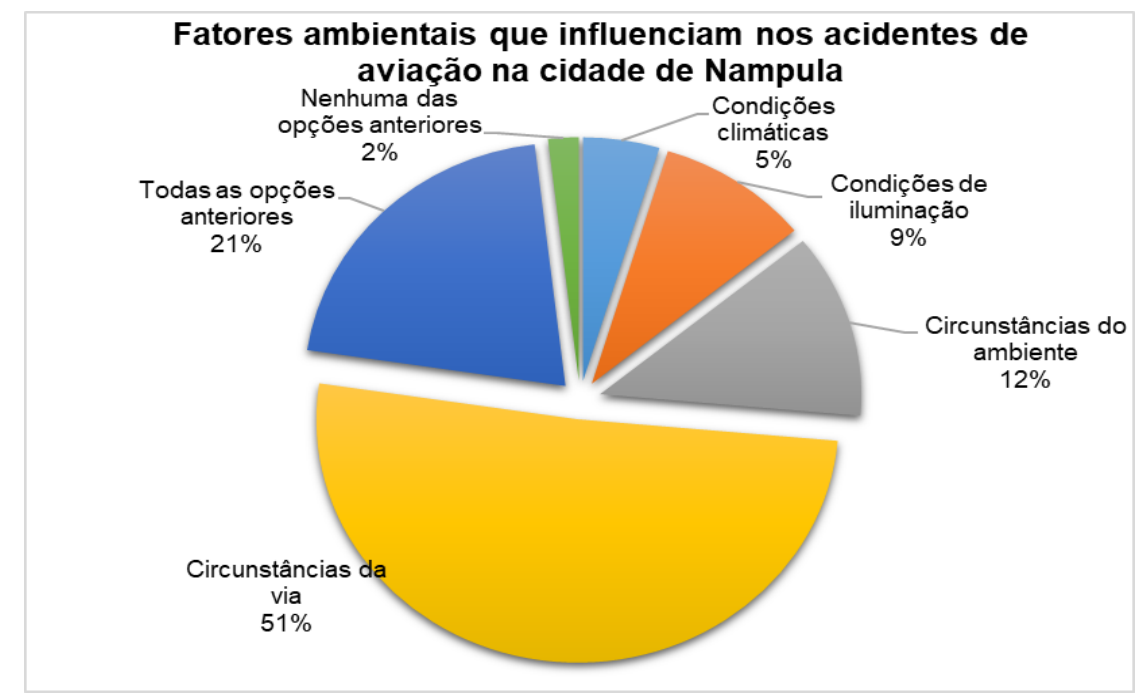

Figura 9. Fatores ambientais que influenciam nos acidentes de trânsito em Nampula.

Dentre os fatores de estrada que influenciam nos acidentes de trânsito na cidade de Nampula (Fig. 10) podemos destacar os defeitos no percurso (44\%), seguida de problema no piso superficial da estrada (28\%) e má sinalização (28 \%). Estes resultados são similares aos do Chagas (2011). No entanto, os defeitos no percurso foram a deficiente condição da pavimentação e as características urbanas da via, sobretudo nos bairros suburbanos. Os problemas no piso superficial identificado no estudo são piso molhado, areia e lama em trechos sem asfalto e alagamento em regiões com baixa circulação de água. E a má sinalização é descrita no estudo pelo condicionamento dos semáforos, falta de sinalização em várias ruas e avenidas da cidade, sobretudo as faixas de pedestres e aproximação de locais que requerem atenção especial, como escolas e mercados.

Almeida et al. (2009) consideram que a condição de estrada é uma questão externa associada à gravidade do acidente, sobretudo a melhor condição de rolamento da pista, quando estiver associado a maior velocidade de tráfego na via, falta de lombas em lugares estratégicos, sinalização defeituosa e falta de fiscalização. Deste modo, não se pretende associar de forma linear a relação entre a qualidade das vias e a possibilidade de ocorrência de acidentes de trânsito, mas estes fatores são síncronos. 


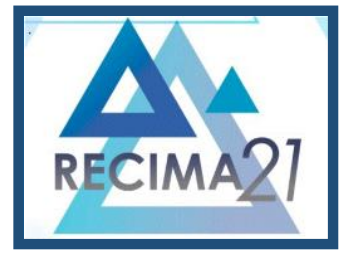

\section{RECIMA21 - REVISTA CIENTÍFICA MULTIDISCIPLINAR}

ESTUDO SOBRE OS FATORES QUE CONTRIBUEM NO ACIDENTE DE TRÂNSITO NA CIDADE DE NAMPULA

António Gonçalves Fortes, Agacane Adelino Mamudo, Momade Jaime Chau, Ernesto Taperero Fernando

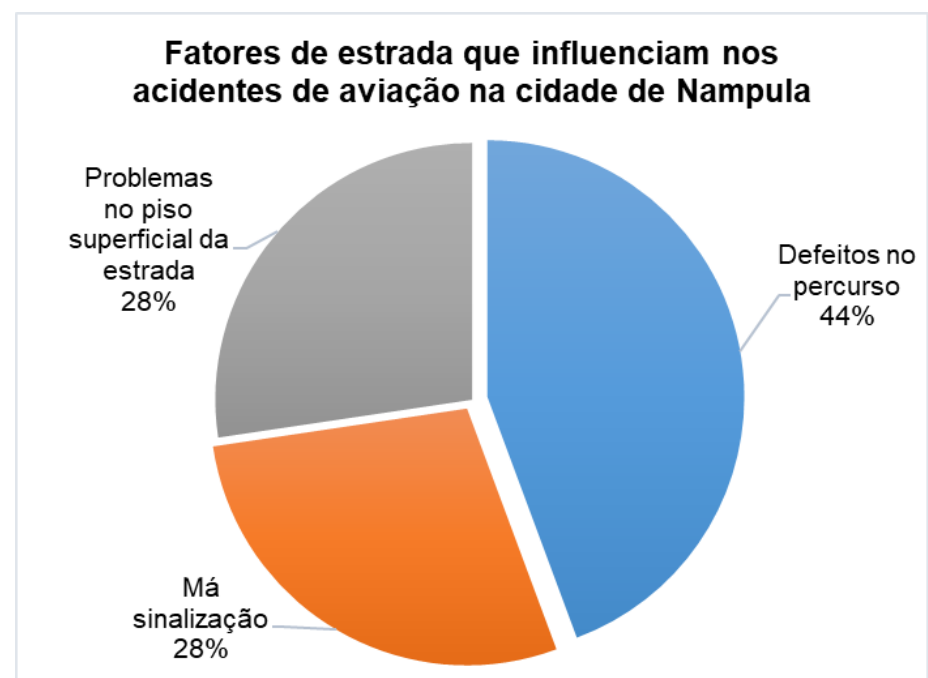

Figura 10. Fatores de estrada que influenciam nos acidentes de trânsito em Nampula.

Os defeitos mecânicos nos veículos é o fator veicular que mais influencia $(45,2 \%)$ nos acidentes de trânsito na cidade de Nampula (Fig. 11), seguida da sobrecarga (14,1\%), visibilidade prejudicada: carga obstruindo ângulos de visão (13,2 \%) e pneus lisos ou com falta de calibragem (13,2 \%). Para além destes fatores, podemos destacar ainda, os retrovisores deficientes $(9,4 \%)$ e faróis com defeitos ou mal ajustados $(4,7)$. Dentre os defeitos mecânicos podemos destacar o desgaste, defeitos ou quebra de pneus, freios, direção, suspensão, transmissão, motor e para-brisas. A sobrecarga e a visibilidade prejudicada verificam-se, principalmente, nos transportes passageiro e de carga. A circulação com veículos com pneus lisos ou com falta de calibragem, retrovisores deficientes e faróis com defeitos ou mal ajustados é resultante da fraca inspeção dos veículos pelo INAV e da fraca fiscalização pelos agentes da PT e PM.

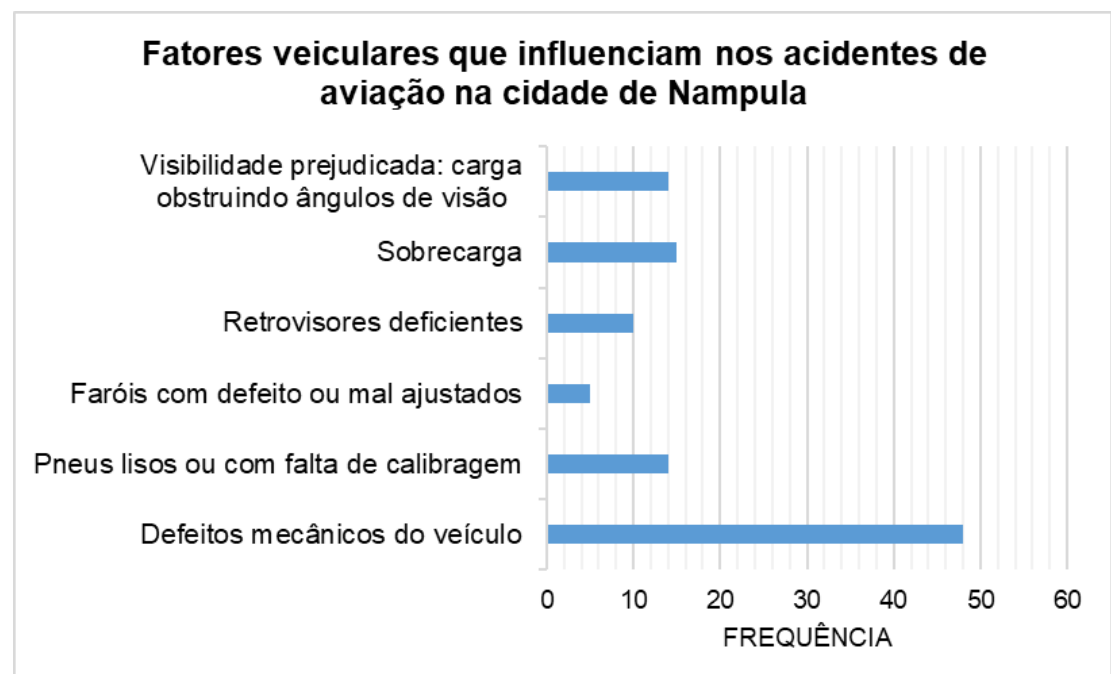

Figura 11. Fatores veiculares que influenciam nos acidentes de trânsito em Nampula. 


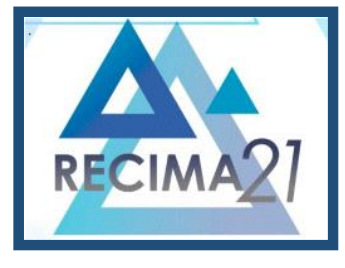

\section{RECIMA21 - REVISTA CIENTÍFICA MULTIDISCIPLINAR}

ESTUDO SOBRE OS FATORES QUE CONTRIBUEM NO ACIDENTE DE TRÂNSITO NA CIDADE DE NAMPULA António Gonçalves Fortes, Agacane Adelino Mamudo, Momade Jaime Chau, Ernesto Taperero Fernando

Em relação aos fatores humanos que influenciam nos acidentes de trânsito na cidade de Nampula (Fig. 12), destacamos o alcoolismo (34\%), seguido do comportamento ou inexperiência do condutor (19,8 \%), a imprudência (17\%) e a debilidade ou distração (13,2 \%). Em menores proporções ainda temos a fadiga (7,5\%), condução sem habilitação (2,8 \%), a visão prejudicada e visibilidade reduzida, ambas com $1 \%$ cada. Todos os fatores humanos mostram a irresponsabilidade de certos condutores, associado ao fraco cumprimento do Código de estrada e baixa fiscalização ou punição pelos agentes da PT e PM. Para inverter o quadro de acidentes resultantes dos fatores humanos, Machava (2011) aponta que deve-se incrementar as fiscalizações rodoviárias, as campanhas de educação, os controlos de álcool, os controlos de velocidade, uma vez que o número de acidentes com vítimas mortais tende a subir. Numa outra abordagem, Almeida et al. (2009) considera que as próprias medidas de controle propostas para redução de acidentes são focalizadas nos fatores humanos, por serem consideradas ações eficazes, normalmente de baixo custo, com potencial de evitar o acidente ou reduzir significativamente sua gravidade. No entanto, para o caso da cidade de Nampula é preciso considerar que estímulos externos, providos pelo sistema viário e seu entorno, podem contribuir para a maior ou menor segurança do trânsito e para a redução ou aumento dos acidentes, tais como, a presença ou ausência de elementos de sinalização, os quais repassam ao condutor muitas informações necessárias, bem como as condições da pista, as quais também interferem no desempenho da tarefa de dirigir um veículo.

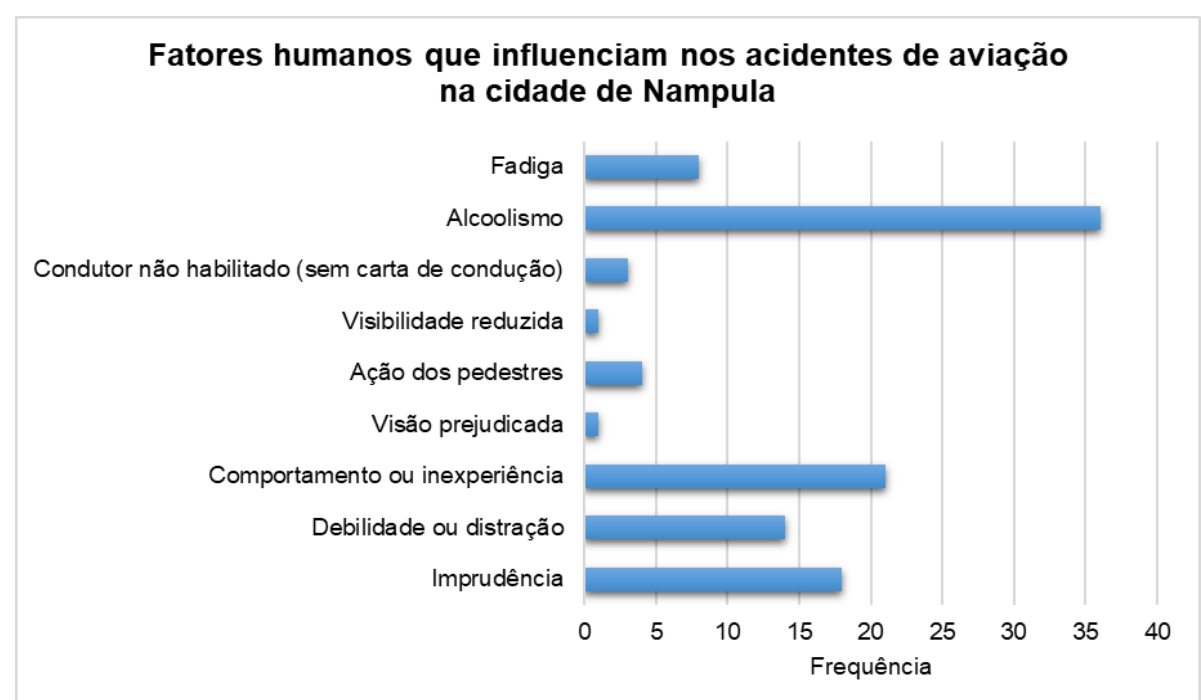

Figura 12. Fatores humanos que influenciam nos acidentes de trânsito em Nampula.

O excesso de velocidade ou velocidade inadequada é o fator imediato que mais influencia $(73,6 \%)$ nos acidentes de trânsito na cidade de Nampula (Fig. 13), seguida das condições pessoais negativas (14,2 \%), deficiência na percepção (8,5 \%) e erros de evasão (3,8 \%). Estes fatores foram definidas por Chagas (2011) e identificados no estudo, como: excesso de velocidade ou velocidade inadequada, exceder o limite de velocidade estabelecido para a via e curvas ou aplicar uma 


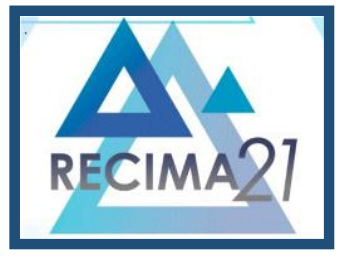

\section{RECIMA21 - REVISTA CIENTÍFICA MULTIDISCIPLINAR}

velocidade insegura para a via sob certas condições climáticas, de veículo ou de trânsito. As condições pessoais negativas, pode se dar por uso de equipamentos eletrônicos, desatenção, cansaço ou soneca ao volante e dirigir doente. A deficiência na percepção pode ser causada pela deficiente visão dos sinais de trânsito, poluição visual, chuvas, vidros ou para-brisa suja ou problemas de visão não corrigidos pelas lentes. Os erros de evasão estão associados a manobras para fugir dos pontos de controle da PT ou PM.

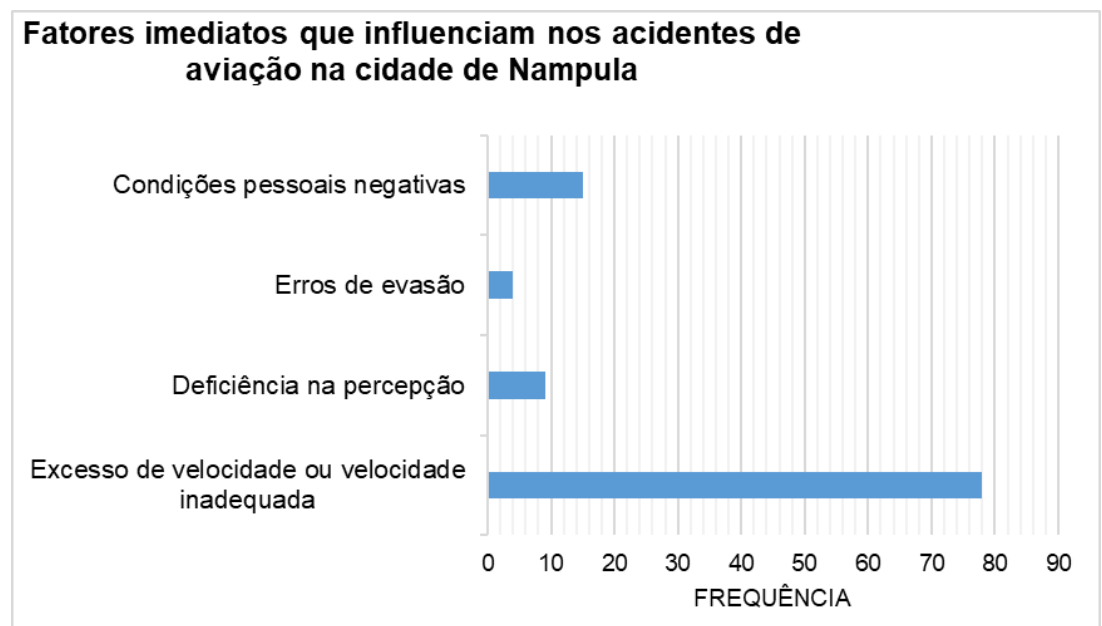

Figura 13. Fatores imediatos que influenciam nos acidentes de trânsito em Nampula.

Os resultados sobre as sugestões dos munícipes para redução dos acidentes de trânsito na cidade de Nampula, dividiu-se em cinco categorias (tabela 4).

Tabela 4. Categorias dos fatores que podem auxiliar na redução dos acidentes de trânsito na cidade de Nampula.

\begin{tabular}{|c|c|}
\hline Categoria & Descrição \\
\hline Pessoais & $\begin{array}{l}\text { - Condução com prudência e respeitar os limites de velocidade das vias, as } \\
\text { sinalizações e as regras de transito; } \\
\text { - Não condizir sob efeito de alcool ou estupefacientes, de fadiga e outros } \\
\text { distrurbios emocionais; } \\
\text { - Obrigação na formação sobre código de estrada aos mototaxistas; } \\
\text { - Que haja mais responsabilidade na parte dos motoristas, uma vez que está a } \\
\text { submeter a vida dele ou de outra pessoa em risco. }\end{array}$ \\
\hline $\begin{array}{c}\text { Educação } \\
\text { cívica }\end{array}$ & $\begin{array}{l}\text { - Educação cívica, sobretudo os mototaxistas e transportadores publicos na } \\
\text { - questao de condução segura e o uso de proteção; } \\
\text { - Conscientização nos utentes sobre as formas corretas de travessia e } \\
\text { comportamento adequado nas estradas; } \\
\text { - Deve intensificar-se a educação rodoviária, no sentido de sensibilizar os } \\
\text { condutores a optarem pela condução defensiva e sobrios; } \\
\text { - Penalização exemplar dos automobilistas infratores. }\end{array}$ \\
\hline $\begin{array}{l}\text { Órgãos de } \\
\text { fiscalização }\end{array}$ & $\begin{array}{l}\text { - Aumentar o número de agentes de PT e PM a monitorar as estradas, não } \\
\text { - Fazeitas subornos e fazer cumprir o codigo de estrada vigente; } \\
\text { - } \text { tomar medidas severas para estes casos; } \\
\text { - Punir os condutores imprudentes e controlar os que sobrecarregam; } \\
\text { - Exigir conhecimento mínimo sobre as regras de trânsito aos mototaxistas e } \\
\text { aumentar a fiscalizacão das vias da cidade }\end{array}$ \\
\hline
\end{tabular}




\section{RECIMA21 - REVISTA CIENTÍFICA MULTIDISCIPLINAR}

ESTUDO SOBRE OS FATORES QUE CONTRIBUEM NO ACIDENTE DE TRÂNSITO NA CIDADE DE NAMPULA António Gonçalves Fortes, Agacane Adelino Mamudo, Momade Jaime Chau, Ernesto Taperero Fernando

- Montagem de retrovisor ou espelhos convexos nas curvas e entroncamento com visibilidade reduzida;

Na via

- Alargamento das vias de acesso e aumentar as faixas de rodagem;

- Criar vias alternativas para acesso ao centro da cidade;

- Melhora os sistemas de sinalização e condições das vias. Colocação de sinalização e lombas em locais com maior frequência de acidentes;

- Colocar limites de velocidades nos redores da cidade.

Nos veículos - Realizar-se frequentemente a inspeção das viaturas;

- Redução da velocidade em lugares de muita aglomeração e controle da parte mecânica antes de se pôr na via.

\section{CONSIDERAÇÕES FINAIS}

De um modo geral, no presente artigo buscou-se identificar, descrever e caracterizar os principais fatores que contribuem nos acidentes de trânsito na cidade de Nampula, parte deles, descritos teoricamente. Estes resultados têm grande importância no conhecimento dos tipos de acidentes, suas correlações (Fig. 14) e mecanismos locais para solucionar ou reduzir o fenômeno com dimensões sociais, económicas, de desenvolvimento e de saúde pública. Pesquisas dessa natureza não visam apenas trazer dados e contribuições teóricas, mas apresentar soluções com vista a reduzir os males causados para as vítimas, seus familiares, o Governo e Municípios, e a sociedade no geral. A deficiente infraestrutura rodoviária e o crescimento acelerado do parque automóvel da cidade de Nampula, sobretudo dos mototaxistas sem instrução básica sobre as regras de trânsito, alterou a circulação urbana e no modo de convivência na urbe, contribuindo negativamente para a ordem nas vias públicas e no trabalho dos agentes de PT e PM, o que favorece nos graves acidentes de trânsito na urbe.

$\mathrm{Na}$ cidade de Nampula, os acidentes mais frequentes são os choques entre motas e o entre automóveis e obstáculos fixos. Estes acidentes ocorrem predominantemente durante os períodos de tarde e noite, nos cruzamentos e entroncamentos. Estes acidentes derivam principalmente dos seguintes fatores (Fig. 14): as circunstâncias da via e do ambiente (fator ambiental), defeitos no percurso, problema no piso superficial da estrada e má sinalização (fator de estrada), defeitos mecânicos, sobrecarga, visibilidade prejudicada e pneus lisos ou com falta de calibração (fator veicular), o alcoolismo, comportamento ou inexperiência do condutor, a imprudência e a debilidade ou distração (fator humano) e o excesso de velocidade ou velocidade inadequada e as condições pessoais negativas (fator imediato).

Concluiu-se que na cidade de Nampula há dificuldades na fiscalização rodoviária e cumprimento do Código de estrada, para além da falta de campanhas de educação cívica e estratégias práticas para 


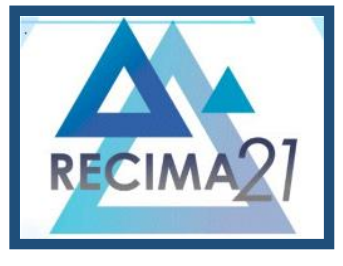

\section{RECIMA21 - REVISTA CIENTÍFICA MULTIDISCIPLINAR}

ESTUDO SOBRE OS FATORES QUE CONTRIBUEM NO ACIDENTE DE TRÂNSITO NA CIDADE DE NAMPULA António Gonçalves Fortes, Agacane Adelino Mamudo, Momade Jaime Chau, Ernesto Taperero Fernando

diminuição dos acidentes de trânsito. Este défice é devido a questões de insuficiência de recursos humanos, materiais e financeiros.

Por isso, sugere-se (Fig. 14), a realização de campanhas de educação cívica, sobretudo aos peões, sobre práticas de travessia segura, e aos mototaxistas e transportadores públicos, sobre uso de proteção e condução segura; realização frequente da inspeção dos automóveis; fazer cumprir o código de estrada vigente no País; aumento da fiscalização nas estradas, sobretudo nas tardes e noites; e melhoraria da sinalização e das condições dos pisos das vias urbanas. Considerando o número elevado de mototaxistas circulando na cidade, propõe-se ainda, ampliar os estudos a respeito desses usuários da via pública especificamente sobre: condições de trabalho, do veículo, dos comportamentos no trânsito e dos riscos de acidentes.

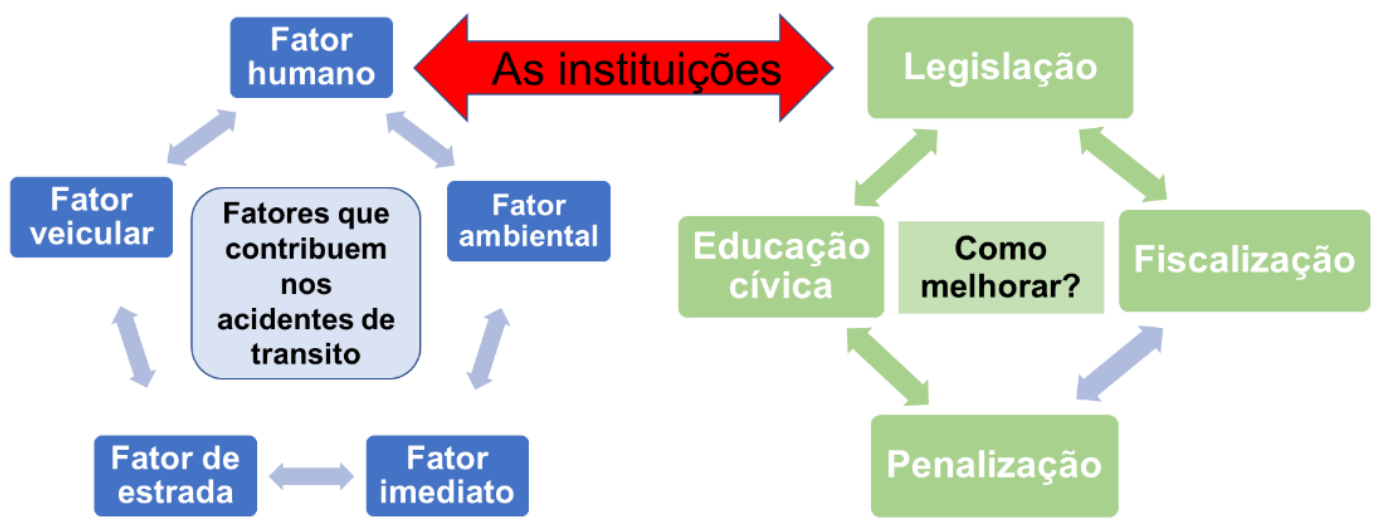

Figura 14. Interelação entre os fatores que influenciam nos acidentes de trânsito em Nampula e possiveis formas de minimizar os efeitos localmente.

\section{REFERÊNCIAS}

ADELAIDE, B.; MATSIMBE, B. Análise da relação entre as características das vias interurbanas e a sinistralidade rodoviárea - caso de estudo: estrada nacional N2, N3, N5 e N6. Porto: INEGI/FEUP, 2017. p. 725-726.

ALMEIDA, L. V. C.; PIGNATTI, M. G.; ESPINOSA, M. M. Principais fatores associados à ocorrência de acidentes de trânsito na BR 163, Mato Grosso, Brasil, 2004. Cadernos de Saúde Pública, v. 25, n. 2, p. 303-312, 2009. DOI: https://doi.org/10.1590/s0102-311x2009000200008

AMODO, N. B.; ZANDAMELA, A. J. Auditoria Inovadora: auditoria em serviço de sinalização horizontal e vertical: inovações nas auditorias de obras públicas. Vitoria: ENAOP, 2009. p. 1-23.

ANE. Estudo preparatório para projecto de melhoria da rede de estradas do corredor de Nacala na República de Moçambique: Resumo do Relatório Final. Moçambique: ANAE, 2018.

CHAGAS, D. M. Estudo sobre fatores contribuintes de acidentes de trânsito urbano.2011. Dissertação (Mestrado em Engenharia de Produção) - Universidade Federal do Rio Grande do Sul, Porto Alegre, 2011.

FERNANDO, E. T. Viabilidade de uso de espelho tráfego como o sistema de segurança rodoviária. 2020. Monografia (Licenciatura em Ensino de Física com habilitações em Energias Renováveis) - Universidade Rovuma, Nampula, 2020. 


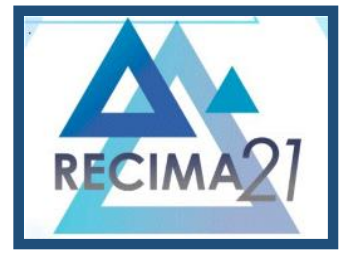

\section{RECIMA21 - REVISTA CIENTÍFICA MULTIDISCIPLINAR}

ESTUDO SOBRE OS FATORES QUE CONTRIBUEM NO ACIDENTE DE TRÂNSITO NA CIDADE DE NAMPULA António Gonçalves Fortes, Agacane Adelino Mamudo, Momade Jaime Chau, Ernesto Taperero Fernando

INE. IV Recenseamento geral da população e habitação: Resultados definitivos. Moçambique: Instituto Nacional de Estatística, 2019.

LUTXEQUE, S. Moçambique lidera o índice de mortes por acidente de viação na CPLP. DW Made for Minds, Nov. p. 4-5, 2018.

MACHAVA, E. J. P. Caracterização da Sinistralidade Rodoviária, na Província de Maputo: estrada nacional $n^{01}$ - Moçambique: uma reflexão do comportamento de condutores e peões. Dissertação (Mestrado em Ciências Policiais) - Instituto Superior de Ciências Policiais e Segurança Interna, Lisboa, 2011.

MAE. Perfil do distrito de Nampula - Província de Nampula. [S. I. : s. n.], 2014.

MANGUANA, F.; NASSABE, J. G. Estatísticas de acidentes de viação - 2017. Moçambique: Instituto Nacional de Estatisticas, 2018.

MANGUANA, F.; NASSABE, J. G. Estatísticas de acidentes de viação - 2018. Moçambique: Instituto Nacional de Estatisticas, 2019.

Manjate, C. J. B. Percepção Social de Risco e Acidente de Viação: Uma Dimensão Sociológica da Sinistralidade Rodoviária na Cidade de Maputo. 2012. Monografia (Licenciatura em Sociologia) Universidade Eduardo Mondlane, Maputo, 2012.

REPÚBLICA DE MOÇAMBIQUE. Decreto - Lei n 1/2011 de 23 de Março. Código da Estrada, Pub. L. No. 1/2011, 155 Moçambique: Boletim da República, 2011.

MUACUVEIA, R. R. M.; FERREIRA, W. R. Ambiente nas áreas de expansão urbana e ocupação irregular do solo na cidade de Nampula - Moçambique. I Fórum Online: Educação, Meio Ambiente e Sustentabilidade, p. 156-172, 2017.

NAÇÕES UNIDAS. Actividades noutras Comissões Regionais das Nações Unidas. In.: Melhorar a Segurança Rodoviária Global: definir objectivos regionais e nacionais para a redução do número de vítimas de acidentes rodoviários. [S. I.]: Comissão Regionais das Nações Unidas Melhoria, 2010. p. $48-70$.

NHAMIRE, B.; MABUNDA, L. Corrupção: a causa oculta dos acidentes de viação. Centro de Integridade Pública, April, p. 1-32, 2014.

SHENGA, C.; MAGUL, P.; NGALE, S. Segurança Rodoviária em Moçambique. Moçambique: Série Dos Policy Briefs Do ISAP, 2014. p. 1-8.

Yin, R. K. Estudo de caso: planejamento e métodos. 2. ed. São Paulo: Bookman, 2005. 